\title{
Chronic Anal Fissure - A Multi Centric Study
}

\section{Abro $\mathrm{AH}^{*}$, Agha AH, Laghari AR, Bhurgari A, Ali S and Ali SA}

Department of Surgery, Liaquat University of Medical and Health Sciences, Jamshoro, Pakistan

Peoples Medical University Nawabshah and Hamdard University Karachi

${ }^{*}$ Corresponding author: Abro AH, Department of Surgery, Liaquat University of Medical and Health Sciences, Jamshoro, Pakistan, E-mail: drahabro@hotmail.com, sasadalishah@gmail.com

Citation: Abro AH, Agha AH, Laghari AR, Bhurgari A, Ali S, et al. (2015) Chronic Anal Fissure - A Multi Centric Study. J Antibiot Res 1(1): 104. doi: 10.15744/2574-5980.1.104

Received Date: June 26, 2015 Accepted Date: September 21, 2015 Published Date: September 24, 2015

\begin{abstract}
Back Ground: Chronic anal fissure is a commonest anal condition of world population and our country is not an exception. Conservative management is initially recommended with creams and oral analgesics. When conservative measures fail despite of recommended length of therapy, surgical option is offered to the affecters. Lateral sphincterotomy is a surgical option recommended and accepted worldwide. The pre amble of the study was to assess lateral sphincterotomy in terms of safety and final outcome for the surgical management of chronic anal fissure.

Patients and Methods: 120 diagnosed cases of chronic anal fissure admitted during 1st June 2013 to 31st May 2014 in the Department of surgery Liaquat university hospital Jamshoro and Peaple's medical university Nawabshah Sindh Pakistan were included in study.

Patients with anal fissure with other peri-anal conditions, recurrent anal fissure, hepatitis positive, and children's were excluded from the study.

The data was recorded and analyzed.

Post-operative follow-up was maintained every two weeks for six visits (12-weeks). Any complication was recorded on history and physical examination.

The data in this descriptive type study was collected in form of frequency distribution table. The means with standard deviation and numerical variables are presented. SPSS version 15.0 for Windows was used to analyze the data.

Results: Out of 120 diagnosed cases of anal fissure, common age group was 31-40 years (49\%) and most of the patients were females with male to female ratio of 1:1.7.

Pain (100\%) was the commonest symptom followed by constipation (82\%). $79 \%$ had posterior fissure, while $20 \%$ patients had anterior fissure, while $1 \%$ patient had anterior as well as posterior fissure.

The mean duration of post-operative hospital stay was 3 days.

All patients turned up for first follow up visit at $2^{\text {nd }}$ week and no complaints were filed except flatus incontinence by only $2 \%$ cases. Total $33 \%$ patients were lost during follow up while only $3 \%$ patients complained flatus incontinence on $6^{\text {th }}$ and $12^{\text {th }}$ week follow up. No recurrence or fecal incontinence was reported by any patient.

Conclusion: Lateral sphincterotomy is safe and effective surgical management for chronic anal fissure with minimal postoperative complications.
\end{abstract}

Keywords: Chronic anal fissure; Lateral sphincterotomy; Outcome

\section{Introduction}

Anal fissure is a very common acute condition that is presented in majority of the world population. It is the most common cause of severe anal pain. The pain may be so severe that patients may avoid defecation for day's altogether, until they are severely constipated. This delay leads to hardening of the stools, which further tears the anoderm during defecation, setting a vicious cycle $[1,2]$.

Classic features of chronic anal fissure are failure to respond conservative therapy, a fibrous anal polyp, an external skin tag (sentinel pile), visible hemorrhoid, hardening at the edges of fissure, exposed fibers of the internal sphincter at the floor of the fissure, infected base of fissure, and a bridged fissure with underlying fistula $[1,2]$.

The treatment of chronic anal fissure is conservative and surgical [3]. The options are anal dilatation, carbon dioxide laser surgery, fissurectomy with dorsal sphincterotomy and lateral sphincterotomy, which was introduced by Eisenhammer in 1951 and was popularized by Notaras in 1969 [1-5]. 
The Standard Task Force of the American Society of Colon and Rectal Surgeons has recommended lateral sphincterotomy as the method of choice for the surgical treatment of chronic anal fissures [6]. This method is most favored worldwide due to its safety, simplicity, minimal anesthesia requirement and good results $[1,4,7]$. However, there are studies which do not report satisfactory results in terms of fecal incontinence and recurrence [3].

The significant risk of persistent disturbance in anal continence has been reported following lateral sphincterotomy, which varies between $0-36 \%$ for flatus, $0-21 \%$ for liquid incontinence, and $0-5 \%$ for solid stool incontinence $[3,8,9]$ while the recurrence rate varies from $0-6 \%[4]$.

The purpose of this study was to assess the safety and outcome results of lateral sphincterotomy at Liaquat University Hospital Jamshoro and Peaple's medical university Nawabshah Sindh Pakistan.

\section{Material and Methods}

This Prospective Case study was conducted in the Department of surgery, Liaquat University Hospital/Jamshoro and Peaple's medical university Nawabshah Sindh from June 1, 2013 to May 31, 2014. During period of study 172 patients presented with chronic anal fissure all were initially advice analgesic, antibiotic, manual anal dilation and high fiber diet. 42 patients respond to conservative management; however response to conservative management was quite unsatisfactory in 124 cases. Therefore they were advice surgical management. 4 patients preferred to wait further and refused for the surgical intervention, 3 patients having history of recent myocardial infarction were excluded and another 3 cases having has haemorroidectomy in the past were also excluded. Finally 120 patients with chronic anal fissure underwent surgical intervention after obtaining written /verbal concern. After baseline investigations done and anesthesia fitness obtained these patients underwent lateral sphincterotomy either under spinal or general anesthesia. As we do not have the facility of anorectal electromanometry, we performed digital rectal examination under anesthesia just before surgery to assess the tone the anal sphincter, while lateral sphincterotomy preceded by digital anal dilatation.

The indoor post-operative and follow-up 12 week data of these patients was recorded on predesigned proforma. Post-operative follow-up was maintained every three weeks for six visits (18-weeks). Any complication especially, incontinence (flatus, liquid and solid stools) and recurrence of symptoms, abscess and non-healing ulcer was recorded.

The data in this descriptive type study were collected in form of frequency distribution table. The means with standard deviation and numerical variables are presented. SPSS version 15.0 for Windows was used to analyze data.

\section{Results}

120 cases of anal fissure were inducted in the study. Frequent age group was 31-40 years (59\%) followed by 41-50 years (27\%) (Figure 1). There was female preponderance with a male to female ration of 1:1.8 (Figure 2). Although pain was presenting feature found in all patients of this series, however its severity and duration varied from patient to patient. Eighty four patients (84\%) had constipation while remaining (16\%) had normal consistency of stool. $78 \%$ had Bleeding per rectum. It was bright red in color and was sufficient enough in most patients to streak the stool and in some to soil the under garments. 36\% patients complained of pruritis ani, while only 3 patients had pussy discharge (Table 1). Out of 120 patients, $93 \%$ had posterior fissure and $23 \%$ had anterior fissure (Table 2).

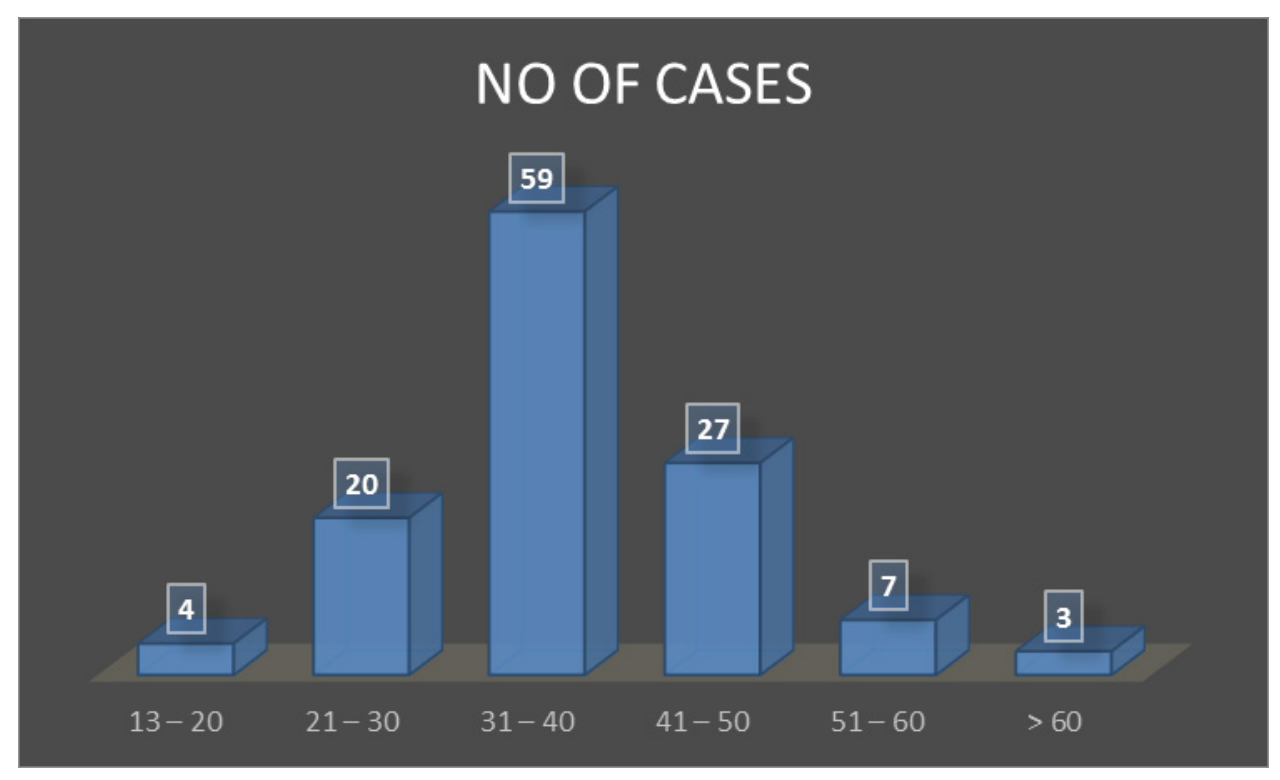

Figure1: Age Distribution 


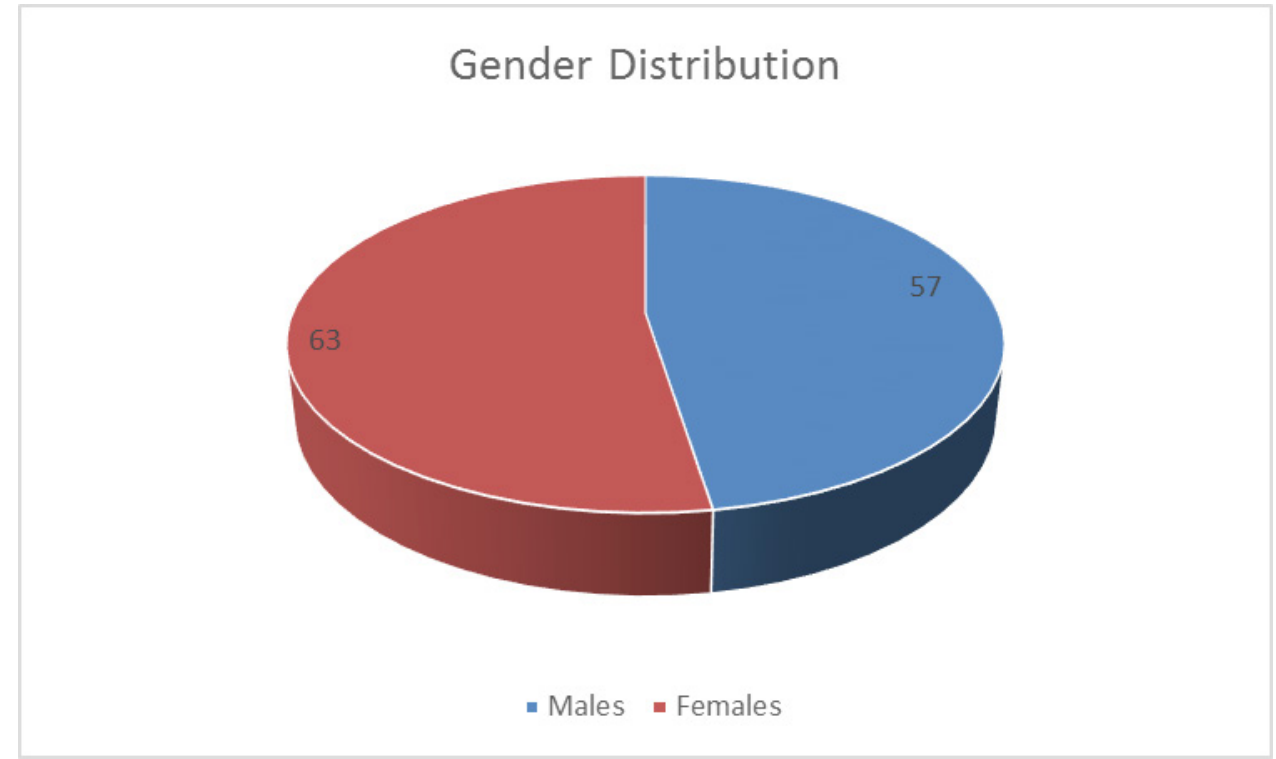

Figure2: Gender Distribution

\begin{tabular}{|c|c|}
\hline Clinical Feature & Frequency \\
\hline Pain & 100 \\
\hline Constipation & 82 \\
\hline Bleeding P/R & 78 \\
\hline Pruritis ani & 36 \\
\hline Discharge & 3 \\
\hline
\end{tabular}

Table1: Presenting Features

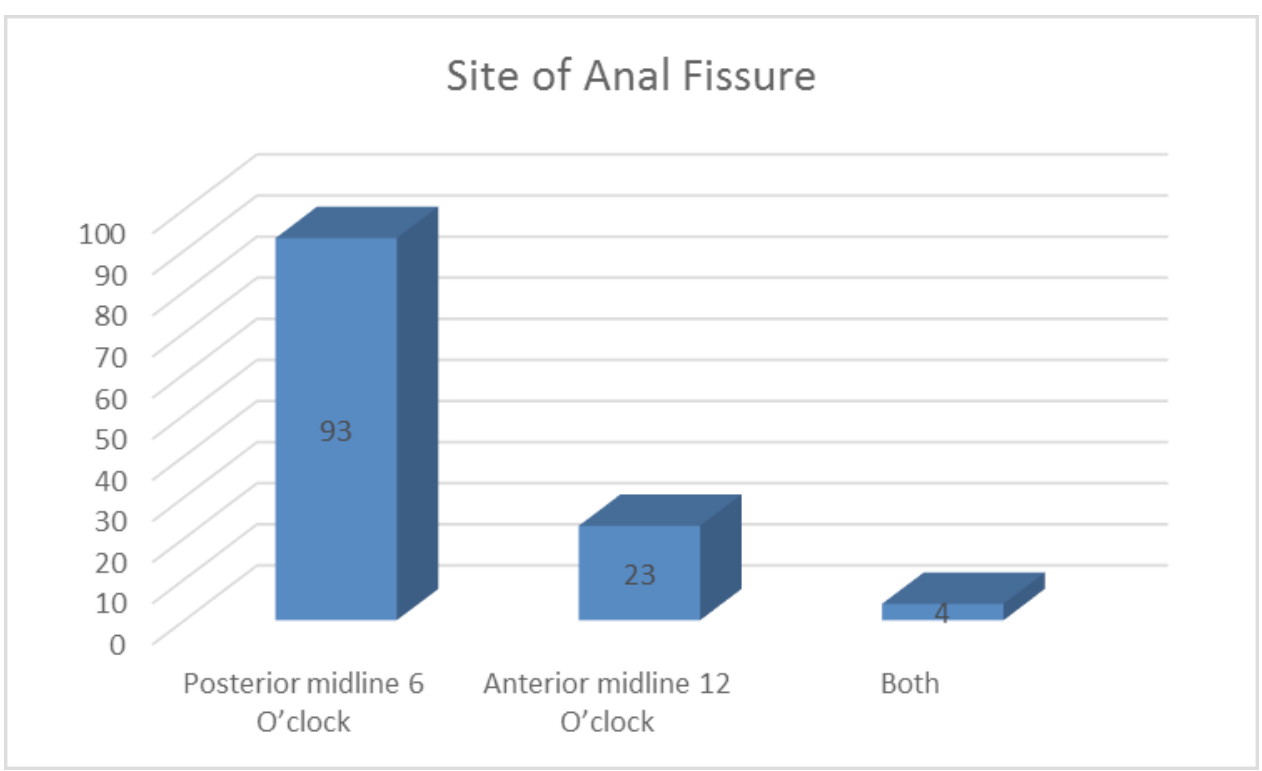

Table 2: Sites of Anal Fissure

The mean duration of hospital stay was 3 days. However wound of 78\% cases took 1 week to heal, $20 \%$ wounds took 2 weeks to heal while only $2 \%$ wounds took longer than 2 weeks to heal (Table 3 ). During this study we observed that after lateral sphincterotomy $89 \%$ of our patients were symptoms free while $11 \%$ had persistence of symptoms but with decreased intensity.

Patients were followed up for 18 weeks. All patients turned up for first follow up visit at $3^{\text {rd }}$ week and no complaints were filed except flatus incontinence by only $2 \%$ cases. Up to $6^{\text {th }}$ week $20 \%$ patients were lost to follow up $3 \%$ more patients (13\%) were lost for follow up till $18^{\text {th }}$ week and 3 patients reported flatus incontinence. No recurrence or faecal incontinence was reported by any patient (Table 4 and 5). 


\begin{tabular}{|c|c|c|}
\hline Healing Time & Frequency & Percentage \\
\hline 1 week & 98 & 98 \\
\hline 2 weeks & 20 & 20 \\
\hline > 2 weeks & 2 & 2 \\
\hline
\end{tabular}

Table 3: Postoperative recovery (healing) time

\begin{tabular}{|c|c|c|}
\hline Complications & Frequency & Percentage \\
\hline Incontinence (flatus) & 2 & 2 \\
\hline Discharge & 2 & 2 \\
\hline Local infection & 3 & 3 \\
\hline Pruritis ani & 10 & 10 \\
\hline
\end{tabular}

Table 4: Complications of LIS

\begin{tabular}{|c|c|r|c|}
\hline & $\mathbf{3}^{\text {rd }}$ Week & $\mathbf{6}^{\text {th }}$ Week & $\mathbf{1 8}^{\text {th }}$ Week \\
\hline Complete follow up & 100 & 80 & 77 \\
\hline Lost follow up & 0 & 20 & 33 \\
\hline Flatus incontinence & 2 & 3 & 3 \\
\hline Fecal incontinence & 0 & 0 & 0 \\
\hline Recurrence & 0 & 0 & 0 \\
\hline
\end{tabular}

Table 5: Follow Up

\section{Discussion}

Chronic anal fissure is the most common cause of anal pain associated with internal anal sphincter hypertonia. Surgical sphincterotomy achieves permanent reduction at sphincter hypertonia [10]. Conservative treatment can only provide temporary reduction [11].

It has been said that all patients reported with anorectal symptoms were worrying about the cancer. Among the other diagnostic possibilities, one of the most common is anal fissure. Anal fissure is a common and distressing problem. This original study is comprised of 120 cases, while Jensen et al. [12] conducted a similar study recruiting 58 subjects, Gui et al. [13] upon only 10 patients. However larger scale studies were also conducted on 1355 patients by Khubchandani et al. in 1989 [14] Anal fissures occur roughly equally in both sexes. However few studies show a male to female ratio of 1:2.6 [15] while other had reported male to female ratio of 2:3 [16]. It is evident from these studies that the most of these patients were females. Similarly in present study most of the patients were females.

Any age group may be affected by anal fissure. However it is uncommon at the extreme of age. In present study the age ranged from 17 years to 61 years with most frequent age group of 31-40 years having 59\% study population followed by $40-50$ years with $27 \%$ comparable to another study [14].

Regarding presentation of the patients, pain is the main symptom which is severe and follows defecation and lasts for many hours. In this study also pain was the most common and consistent feature of 100 patients (100\%) followed by Bleeding per rectum (78\%) which was bright red and sufficient enough to streak the stool and Constipation (82\%) while 36 patients (36\%) had pruritis ani and discharge was seen in 3 patients (3\%). The fissure is always situated in the vertical axis of the anal canal. The usual site for anal fissure is mid line; however lateral fissures are seen in diseases like Crohn's disease, ulcerative colitis, tuberculosis, syphilis and HIV etc. In this study $93 \%$ of the patients had single fissure posteriorly and $23 \%$ had fissures anteriorly. However $4 \%$ patients had fissure both anteriorly and posteriorly. These results are also at par with the results of Fiducia G et al. [17] who reported 89\% posterior midline fissure, $6.5 \%$ anterior and $4.5 \%$ synchronous anterior and posterior fissures. During this study we observed that after lateral sphincterotomy $89 \%$ of our patients were symptom free, while $11 \%$ had persistence of symptoms but with decreased intensity. These results are comparable to other studies i.e. Viso Pons et al. [18] and Rosa G et al. [19] also reported similar results i.e. $95 \%$ symptomatic relief.

Mean hospital stay of patients in this study was 3-days while wound healing time was 27 days. Out of 100 patients $3 \%$ had flatus incontinence and none had reported fecal incontinence. These results are again at par with other studies; like Pernlkoff et al. [17] who reported $4.4 \%$ flatus incontinence and $0.04 \%$ fecal incontinence. However Rosa G et al. [19] reported only $0.04 \%$ gas incontinence.

Recurrence was not reported by any patients in this study within 6 months follow up period. Similar results were also reported by other researchers like Cho et al. [20], and Milito et al. [21] who observed no recurrence. However Casillas et al. [22] reported 5.6\% recurrence of fissure in ano.

As discussed above it is obvious that lateral sphincterotomy has satisfactory results with regard to symptomatic relief, incontinence and recurrence of fissure in ano. 


\section{Conclusion}

We conclude that lateral internal sphincterotomy is a safe and effective treatment of choice for chronic anal fissure due to symptomatic relief and rare impairment of continence to flatus and feces and less chances of recurrence.

\section{References}

1. Ahmad N, Aziz M, Faizullah (2004) Closed lateral internal sphincterotomy under local anesthesia in OPD in the treatment of chronic anal fissure. Ann King Edward Med Uni 10:11-2.

2. Farooq A, Niaz Z (2003) Comparative study of lateral internal sphincterotomy verses topical glyceryl trinitrate for treatment of fissure-in-ano. Ann King Edward Med Uni 9: 278-81.

3. Sokol T, Marks JW Anal fissure (torn rectum) - causes and treatment options.

4. Ram E, Alper D, Stein GY, Bramnik Z, Dreznik Z (2005) Internal anal sphincter function following lateral internal sphincterotomy for anal fissure: a long-term manometric study. Ann Surg 242: 208-11.

5. Poritz LS (2006) Anal fissure. E Med J Medscape spec.

6. Lindsay I, Cunningham C, Jones OM, Francis C, Mortensen NJ ( 2004) Fissurectomy-botulinum toxin: a novel sphincter-sparing procedure for medically resistant chronic anal fissure. Dis Colon Rectum 47: 1947-52.

7. Gillett BP, Paidas CN (2006) Anal fissure. E Med J Medscape spec.

8. Nariani MG, Chaturvedi R, Jatania J Anal fissure: a comparison of conservative treatment versus surgical methods. BHJ Issue Special.

9. Gupta PJ (2006) Treatment of anal fissure - revisited. Shiraz E-Med J 7: 1-7.

10. Liratzopoulos N, Efremidou EI, Papageorgiou MS, Kouklakis G, Moschos J, et al. (2006) Lateral subcutaneous internal sphincterotomy in the treatment of chronic anal fissure: our experience. J Gastrointestin Liver Dis 15: 143-7.

11. Fiducia G, Bosco V (2006) Partial left lateral subcutaneous sphincterotomy for anal fissure: role and results. Chir Ital 58: 501-4.

12. Jensen SL, Lund F, Nielson OV, Tange G (1984) Lateral subcutaneous sphincterotomy versus anal dilatation in the treatment of fissure-in-ano in outpatients: a prospective randomized study. Br Med J 289: 528-30.

13. Gui D, Cassetta E, Anastasio G, Bentivoglio AR, Maria G, et al. (1994) Botulinum toxin for chronic anal fissure. Lancet 344: 1127-8.

14. Cohen A, Dehn TC (1995) Lateral subcutaneous sphincterotomy for the treatment of anal fissure in children. Br J Surg 82: 1341-2.

15. Mazier WP (1985) Keyhole deformity: fact and fiction. Dis Colon Rectum 28: 8-10.

16. Khubchandani IT, Reed JF (1989) Sequelae of internal sphincterotomy for chronic fissure-in-ano. Br J Surg 76: 431-4.

17. Pernikoff BJ, Eisenstat TE, Rubin RJ, Oliver CG, Salvati EP (1994) Reappraisal of partial lateral sphincterotomy. Dis Colon Rectum 37: 1291-5.

18. Viso Pons L, Beatobe Muntada J (1989) Internal lateral sphincterotomy results. Rev Esp Enferon Dig 75: 589-92.

19. Rosa G, Lolli P, Piccinelli D, Mazzola F, Zugni C et al. (2005) Calibrated lateral internal sphincterotomy for chronic anal fissure. Tech Coloproctol 9: 127-31.

20. Cho DY (2005) Controlled lateral sphincterotomy for chronic anal fissure. Dis Colon Rectum 48: 1037-41.

21. Milito G, Arullani A, Brancaleone C, Cesca D, Filingeri V et al. (1983) Subcutaneous lateral internal sphincterotomy in the treatment of chronic anal fissure. Ital J Surg Sci 13: 275-9.

22. Casillas S, Hull TL, Zutshi M, Trzcinski R, Bast JF (2005) Incontinence after a lateral internal sphincterotomy: are we underestimating it? Dis Colon Rectum 48: 1193-9. 